DUARTE, $A . A$. $d e$ $L$; TOFANINI, $B . P . ;$ REZENDE, $M$. G. G.; DUARTE, $R$. $V . d e$

$L$.

\begin{tabular}{c|c|c}
\hline ISSN 2525-4812 (versão online) & Revista Terceira \\
ISSN 2238-7641 (versão impressa) \\
$\begin{array}{c}\text { http://www.revistaterceiramargem.com/ } \\
\text { index.php/terceiramargem/index }\end{array}$ & $\begin{array}{c}\text { Recebido em: 19/6/2019 } \\
\text { Aprovado em: 30/2/2020 } \\
\text { Período de publicação: jul/dez, 2020 }\end{array}$ & $\begin{array}{c}\text { Margem Amazônia } \\
\text { Margem Ama } \\
(\text { v. } 6 \cdot \text { n. 15 } \cdot \text { Jul/Dez 2020) }\end{array}$ \\
\hline
\end{tabular}

Como citar o artigo:

DUARTE, A. A. de L; TOFANINI, B. P; REZENDE, M. G. G; DUARTE, R. V. de L. A relevância das cartilhas socioambientais a partir da interação sociedade e universidade. Revista Terceira Margem Amazônia, v. 6, n.15, p. 256-270, 2020. Doi: http://dx.doi.org/10.36882/2525-4812.2020v6i15p256-270.

\title{
A RELEVÂNCIA DAS CARTILHAS SOCIOAMBIENTAIS A PARTIR DA INTERAÇÃO SOCIEDADE E UNIVERSIDADE
}

\author{
Alexa Andrinne de Lima Duarte \\ Beatriz Pellizzari Tofanini ${ }^{2}$ \\ Marília Gabriela Gondim Rezende ${ }^{3}$ \\ Rosangela Viana de Lima Duarte ${ }^{4}$
}

\begin{abstract}
Resumo: As ferramentas de comunicação são importantes arquétipos, capazes de interligar a universidade e a sociedade, em suas múltiplas facetas. Este artigo apresenta uma discussão teórica que foi realizada por meio de pesquisa bibliográfica em diversas bases de dados acadêmicas, buscando compreender a relevância das cartilhas socioambientais a partir da interação sociedade e universidade. Para atingir esse objetivo foram traçados inúmeros procedimentos metodológicos, como entrevistas abertas, rodas de conversas e formulários. Nas últimas décadas têm-se evidenciado inúmeros problemas ambientais, que por vezes são impulsionados por barreiras de comunicação e insuficientes ferramentas de educação ambiental em linguagem adequada a cada contexto, criadas e aplicadas coletivamente, como forma de compreender os fatores limitantes e potencializadores da produção nas terras florestais, e águas de trabalho. Os instrumentos de educação ambiental são importantes dispositivos veiculadores de conhecimentos, tecnologias sociais e inclusão produtiva. Os resultados apontam a necessidade de ampliação das ferramentas de comunicação na contemporaneidade. Portanto, faz-se necessário a execução de novos estudos e pesquisas relacionados à temática, visando ampliar a interação universidade e sociedade.
\end{abstract}

Palavras Chave: Educação Ambiental, ferramentas de comunicação, sustentabilidade.

Abstract: Communication tools are important archetypes, capable of interconnecting the university and society, in its multiple facets. This article presents a theoretical discussion that was carried out through bibliographic research in several academic databases, seeking to understand the relevance of socio-environmental booklets from the interaction between society and university. To achieve this goal, numerous methodological procedures were designed, such as open interviews, rounds of conversations and forms. 
In recent decades, numerous environmental problems have been evidenced, which are sometimes driven by communication barriers and insufficient environmental education tools in language appropriate to each context, created and applied collectively, as a way of understanding the limiting and potentiating factors of production in forest lands, and working waters. Environmental education instruments are important devices that convey knowledge, social technologies and productive inclusion. The results point to the insufficiency of data in the academic bases, which highlights the need to expand communication tools today. Therefore, it is necessary to carry out new studies and research related to the theme, aiming to expand the interaction between university and society.

\footnotetext{
${ }^{1}$ Graduanda em Engenharia Florestal, UFAM, E-mail: alexa.floresteira@gmail.com

${ }^{2}$ Graduanda em Engenharia Florestal, UFAM, E-mail: biatofanini@ gmail.com

3Doutora em Ciências Ambientais, UFAM, E-mail: mariliageoufam@gmail.com

${ }^{4}$ Mestre em Ciência e Engenharia de Materiais, UFAM, E-mail: vianaa.rosa@gmail.com
}

Keywords: Environmental education, communication tools, sustainability.

\section{INTRODUÇÃO}

Primeiramente, é importante compreender o conceito de Educação Ambiental que trata-se dos processos por meio dos quais o indivíduo e a coletividade constroem valores sociais, conhecimentos, habilidades, atitudes e competências voltadas à conservação do meio ambiente, bem de uso comum do povo, essencial à sadia qualidade de vida e sua sustentabilidade (BRASIL, 1999). Segundo Saviani (1995):

\footnotetext{
[...] o trabalho educativo é o ato de produzir, direta e intencionalmente, em cada indivíduo singular, a humanidade que é produzida histórica e coletivamente pelo conjunto dos homens. Assim, o objeto da educação diz respeito, de um lado, à identificação dos elementos culturais que precisam ser assimilados pelos indivíduos da espécie humana para que eles se tornem humanos e, de outro lado e concomitantemente, à descoberta das formas mais adequadas para atingir esse objetivo (SAVIANI, p. 17, 1995).
}

A lei n 9.795, de 27 de abril de 1999, discorre sobre a Educação Ambiental, institui a Política Nacional de Educação Ambiental e dá outras providências. Segundo essa Lei, a Educação Ambiental é um componente essencial e permanente da educação nacional, devendo estar presente, de forma articulada, em todos os níveis e modalidades do processo educativo, ou seja, educação de crianças, jovens e adultos, em caráter formal e informal. A Educação Ambiental tem sua importância alicerçada no fato de garantir a 
DUARTE, $A . A$. $d e$ L; TOFANINI, $B . P$. ; REZENDE, $M$. G. G.; DUARTE, $R$. $V . d e$

duração das ações de gestão ambiental por meio das mudanças de comportamentos e da consciência ambiental da sociedade como um todo. Deste modo, não adianta muito desenvolver ações de gestão ambiental se a sociedade não estiver devidamente preparada, bem como de mente aberta para receber os novos saberes (SEIFFERT, 2009). Logo, é imprescindível a aplicação da Educação Ambiental no seio de uma sociedade, respeitando as práticas culturais ali existentes, construindo através das trocas de saberes um conhecimento em conjunto (MELLO e TRAJBER, 2007).

Contudo, o conceito de Meio Ambiente é expressado no art. $3^{\circ}$, I, da Lei 6.938, de 31.8.81, que o define como o conjunto de condições, leis, influências, alterações e interações de ordem física, química e biológica que permite, abriga e rege a vida em todas as suas formas. E em 1988, através da Constituição Federal, uma nova perspectiva do conceito de Meio Ambiente foi abordada, por meio dessa entende-se que o meio ambiente se divide em natural, cultural, artificial e do trabalho.

O Meio ambiente natural é formado pelo solo, a água, o ar, flora, fauna e todos os demais elementos naturais responsáveis pelo equilíbrio dinâmico entre os seres vivos e o meio em que vivem (art.225, caput e $\S 1^{\circ}$ da CF).

O Meio ambiente cultural é aquele composto pelo patrimônio histórico, artístico, arqueológico, paisagístico, turístico, científico e pelas sínteses culturais que integram o universo das práticas sociais das relações de intercâmbio entre homem e natureza (art. 215 e 216 da CF).

O Meio ambiente artificial é o constituído pelo conjunto e edificações, equipamentos, rodovias e demais elementos que formam o espaço urbano construído (art. 21, XX, 182 e segs. art. $225 \mathrm{CF})$.

O Meio ambiente do trabalho é o integrado pelo conjunto de bens, instrumentos e meios, de natureza material e imaterial em face dos quais o ser humano exerce as atividades laborais (art. 200, VII CF).

Partindo desse contexto, esse artigo teve como objetivo analisar a relação entre a aplicação de cartilhas socioambientais e o desenvolvimento local. As cartilhas aplicadas e analisadas foram sobre a construção de hortas comunitárias, plantio de mudas, controle de pragas, formas de utilização sustentável dos recursos naturais, reciclagem, produção e plantio de mudas, montagem de herbário, compostagem, além de irrigação, coleta, armazenagem e germinação de sementes nativas. Além disso, incentiva e demonstra a 
DUARTE, $A$. $A$. de L; TOFANINI, $B . P . ;$ REZENDE, $M$. . . G.; DUARTE, $R$. $V . d e$

importância do protagonismo dos comunitários para a conservação da sociobiodiversidade, estimulando o desenvolvimento local sustentável por meio de ferramentas de educação ambiental, promovendo o processo de construção do conhecimento coletivo e fortalecendo os valores e saberes locais.

\section{METODOLOGIA}

A presente pesquisa centrou-se nas seguintes categorias: Ferramentas de comunicação, Educação Ambiental e Sustentabilidade, preconizadas pelos autores João Bottentuit (2007) e Pedro Jacobi (2003), respectivamente, pautando-se em um processo de transformação da realidade socioambiental. Para atingir o objetivo delineado anteriormente foi utilizada uma variedade de ferramentas, devido à complexidade do tema e de novos paradigmas constituídos por uma nova sociedade ambientalmente sustentável. O trabalho foi desenvolvido na Comunidade São Francisco, localizada no Careiro da Várzea, no Amazonas (Figura 1).

Figura 1: Mapa da Ilha do Careiro, Amazonas

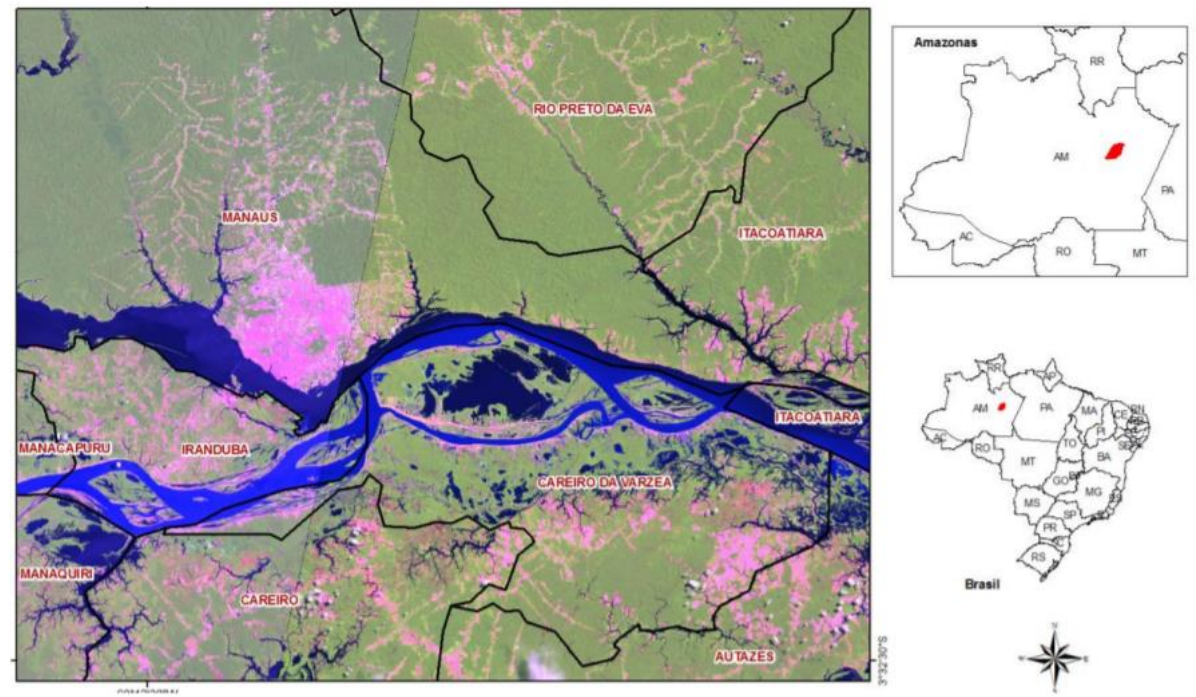

Fonte: Instituto Brasileiro do Meio Ambiente e dos Recursos Naturais Renováveis (IBAMA) - 2011

Org.: VASCONCELOS, 2016

Esse artigo, oriundo dos resultados do Projeto de extensão intitulado "Cartilhas socioambientais: construção e aplicação de ferramentas de Educação Ambiental" esboça a relevância dessas ferramentas de comunicação para as comunidades rurais do 
DUARTE, $A . A$. $d e$ L; TOFANINI, $B . P$. ; REZENDE, $M$. G. G.; DUARTE, $R$. $V . d e$

Amazonas. Primeiramente, os pesquisadores, por meio de questionários, realizaram consultas prévias sobre as principais dificuldades enfrentadas pelos agricultores da área de estudo. Em seguida, foram utilizados formulários e entrevistas abertas, com grupos focais, para a elaboração das cartilhas, que foram disponibilizadas na Plataforma do Facebook (Figura 2).

Figura 2: Página do Facebook criada para a divulgação das cartilhas socioambientais.

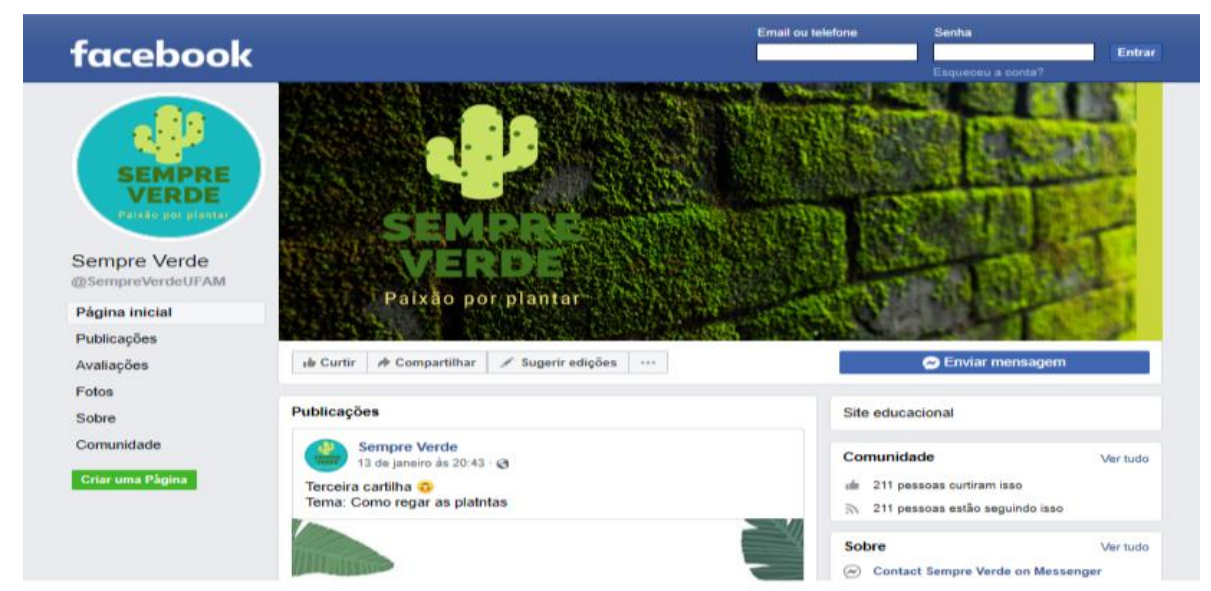

Fonte: Alexa et al

A metodologia empregada na elaboração da cartilha foi baseada em algumas etapas: definição do objetivo da cartilha com todos os envolvidos, posteriormente promoveu-se uma seleção das melhores ideias e, por fim, buscou-se definir qual seria efetivamente a mensagem principal e as mensagens específicas a serem transmitidas.

As cartilhas socioambientais, em formato digital, foram confeccionadas pela equipe do projeto, baseado nas atividades desenvolvidas na Comunidade São Francisco e disponibilizadas na plataforma do Facebook na página intitulada Sempre Verde, cujo link está descrito abaixo: https://www.facebook.com/SempreVerdeUFAM. As cartilhas socioambientais (Figura 3) abordam temas como Compostagem Caseira, Bonsai de Romã e Rega de plantas, elas foram elaboradas utilizando figuras do Flaticon com o auxílio do programa Power Point. 
DUARTE, $A . A$. $d e$ $L$; TOFANINI, $B . P$. ; REZENDE, $M$. G. G.; DUARTE, $R$. $V . d e$

$L$.

Figura 3: Cartilhas socioambientais

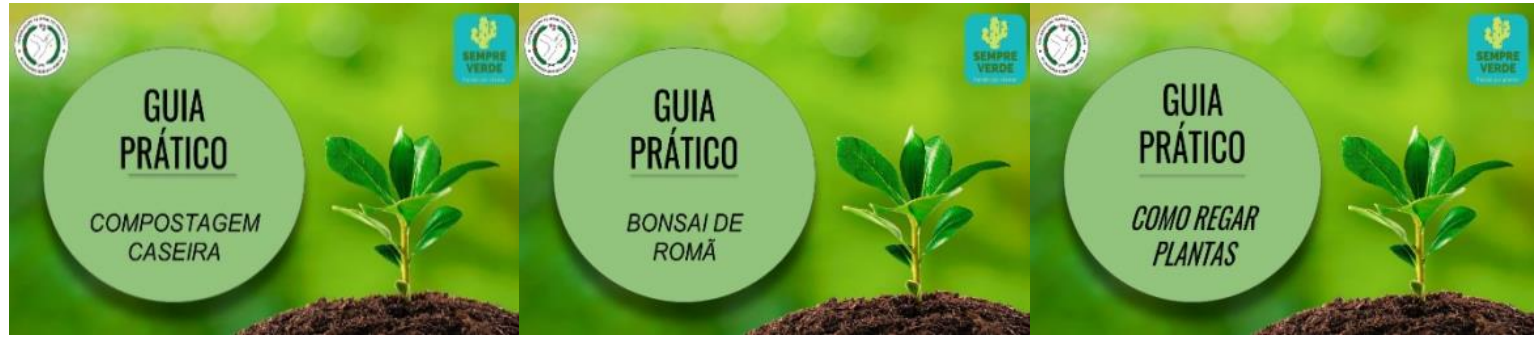

Fonte: Alexa et al

É importante destacar que as cartilhas socioambientais foram confeccionadas pela equipe do projeto de extensão, baseado nas demandas observadas na comunidade em questão. Foram disponibilizadas de forma digital na plataforma do Facebook e serão disponibilizados também de forma impressa, em papel reciclado. Portanto, o percurso metodológico que precedeu a construção das cartilhas consistiu nas seguintes etapas:

- Diálogo com a comunidade;

- Observação das demandas coletivas;

- Promoção da ferramenta "tempestades de ideias";

- Definição dos temas das cartilhas;

- Definição dos objetivos das cartilhas;

- Definição efetiva da mensagem principal;

- Definição das mensagens específicas a serem transmitidas;

- Confecção das Cartilhas, que se deu por meio da ferramenta PowerPoint;

- Disponibilização das cartilhas na plataforma do Facebook;

- Disponibilização das cartilhas impressas em papel reciclável;

\section{RESULTADOS E DISCUSSÃO}

Com o intuito de colaborar com ações coordenadas que incrementem as iniciativas de Educação Ambiental nas universidades, como promotora da educação superior nos seus diferentes conhecimentos, é de suma importância que haja a interação entre a sociedade e a universidade. Neste contexto, as atividades que buscam resgatar o seu papel social, o de integração da comunidade auxilia e fomenta a produção de insumos para promoção da Educação Ambiental de maneira transversal (PRADO et al. 2009). 
O meio ambiente é um complexo de ecossistemas (composto por solo, água, ar, flora, fauna, e os demais elementos) que norteiam a existência humana, em seus múltiplos horizontes. Todavia, nas últimas décadas, têm-se evidenciado inúmeros problemas ambientais, com destaque para os processos de degradação ambiental, que por vezes é gerado por barreiras de comunicação e insuficientes ferramentas de Educação Ambiental, criadas e aplicadas coletivamente. Assim, os arquétipos de educação ambiental tornaramse importantes instrumentos veiculadores de conhecimentos, tecnologias sociais e inclusão produtiva. A escassez dessas ferramentas, principalmente em linguagem adequada, não facilita a compreensão dos fatores limitantes e potencializadores da produção nas terras, florestas e águas de trabalho (CHIOFI e OLIVEIRA, 2014)

A cartilha é uma ferramenta pedagógica que viabiliza a efetivação da difusão da Educação Ambiental, e possui temas diversos. Têm como proposta principal a promoção da sustentabilidade ambiental, a partir da construção e aplicação de um material ilustrado, com linguagem simples, acessível e didática que esclarece dúvidas através de explicações e representações imagéticas, facilitando a decodificação por parte dos sujeitos partícipes. As cartilhas socioambientais precisam atingir igualmente aos sujeitos, independente das condições sociais, econômicas, ética, e cultural de cada sujeito (PARANÁ, 2008).

A aquisição de conhecimentos e habilidades, por meio da Educação Ambiental atua, é um processo de educação política que possibilita também formação de sujeitos sociais de atitudes que se convertem em práticas de cidadania. Por isso, a utilização de cartilhas é uma das possibilidades de promoção da Educação Ambiental (REIS et al, 2012).

No Brasil, percebe-se um aumento, nos últimos anos, de publicações sobre o tema em foco. Entretanto, ainda há quem insista em considerar as cartilhas como uma forma superficial de aprendizagem, ou apenas como uma maneira lúdica de despertar o interesse. As cartilhas devem ser um meio, nunca um fim. Como incentivo à leitura, pode ser um mobilizador da comunidade, não somente acadêmica. Sem dúvida, deveria ser trabalhada com inteligibilidade para conseguir que, a partir dali o aluno se interesse por diversos formatos de leitura.

Este crescente interesse do público pelas cartilhas pode trazer benefícios educacionais nas instituições de ensino. Devemos ressaltar que, para a disseminação do conhecimento por meio de cartilhas, é imprescindível zelar por uma linguagem acessível ao público alvo, para tal deve-se gozar de autonomia linguística, além de abusar de 
mecanismos para representação de elementos narrativos, priorizando a dinamização do conteúdo para que desta forma se evite o "tédio" do leitor e a perda de interesse. A somatória da linguagem visual, do design e da linguagem textual, normalmente presente na mídia, em forma de narrativa, gera uma linguagem única que amplia as possibilidades de comunicação (SANTOS; CRUZ; HORN, 2011).

Pode-se inferir que a execução das cartilhas socioambientais permitiu a interação entre a academia e sociedade, sob estruturas interdisciplinares. Portanto este trabalho tornou-se indispensável na formação dos estudantes que participaram, pois contribuiu significativamente na qualificação e no intercâmbio de conhecimentos com a sociedade, além da formação de profissionais inseridos em um contexto social de uma comunidade rural, superando barreiras e entraves.

Tanto a academia quanto a sociedade foram beneficiadas, pois a interação entre o discente e os sujeitos partícipes proporcionou o desenvolvimento de ambos, enriquecendo a formação do aluno e estimulando a geração de impactos positivos na vida dos comunitários. Além dos fatores supracitados, estabeleceu a troca de saberes e conhecimentos sistematizados. Ademais, foi por meio da prática da extensão rural construtivista que os agricultores, pescadores e extrativistas puderam compreender a complexificação, ou seja, a multiplicidade de elementos necessários para atingir a sustentabilidade e autonomia com base na cooperação e na participação social. A sustentabilidade integra e fortalece valores coletivos, baseada nas práticas educativas contextualizadas, que fornece um aporte para ambientes pedagógicos, possibilitando atitudes de reflexão e ação em torno da problemática ambiental.

Os resultados apontam que as cartilhas socioambientais contribuíram para a inclusão produtiva, pois a construção desses materiais envolveu desde a formação de cidadãos integrados ao mundo do trabalho até o estímulo à autonomia e à busca de uma sociedade voltada à sustentabilidade.

As cartilhas irão contribuir também para a construção das bases do desenvolvimento regional da Comunidade São Francisco, por meio da ampliação da dinâmica produtiva, da produtividade, e da evidenciação das estruturas de cooperação voltadas ao exercício do cooperativismo, que é um importante aliado do desenvolvimento regional, uma vez que facilita o acesso às políticas públicas.

As ferramentas de educação ambiental, apresentadas em forma de cartilhas, expressaram na dimensão conteudal a criação e aplicação de tecnologias sociais, voltadas 
à produção agrícola. A comunicação em ambientes virtuais é fundamental para o ensino e a aprendizagem no contexto da sociedade global em que vivemos, tornando a disponibilização das cartilhas em plataforma on-line imprescindível, além de terem sido disponibilizadas em forma impressa em papel reciclável levando sempre a questão da sensibilização e sustentabilidade em consideração.

A Educação Ambiental é um mecanismo de transformação socioambiental por meio da participação e engajamento da comunidade, faz com que a educação se metamorfoseie em uma prática política que só se concretiza com a cooperação mútua entre cidadãos que sejam sensibilizados com as causas socioambientais. Ao criar espaços críticos de aprendizagem, que podem ser tanto dentro quanto fora da escola, gera-se a união com movimentos sociais organizados (GIROUX, 2003). Nesse sentido, este artigo partiu de um arcabouço metodológico não hierarquizado, pautado na participação direta de alunos, professores, e comunidade, em uma complexificação dinâmica (TRISTÃO, 2007).

Há uma perspectiva crítica da educação ambiental que abrange a possibilidade da elaboração de projetos pedagógicos que aprofundem valores comunitários e estimulem diálogos para que assim o processo de aprendizagem se dê de forma participativa e democrática, por meio de estratégias metodológicas colaborativas, de vivência cultural e ambiental. Esse novo paradigma possibilita que sujeitos sociais se envolvam em projetos onde seu trabalho se torne transformador, ressignificando conhecimento e vida (GIROUX, 2003).

Nesse sentido, essas ferramentas possibilitaram à comunidade acadêmica o contato com a realidade social da área de estudo, por meio do diálogo com diferentes grupos sociais, nos diversos campos da ação profissional, promovendo o processo de construção do conhecimento. Na contemporaneidade há um significativo avanço rumo à uma sociedade conchavada em valores sustentáveis e às causas básicas que estimulam atividades ecologicamente corretas. Entretanto, o desconhecimento incitado por instituições sociais, déficit nos sistemas de informação e de comunicação, além de valores individualistas, competitivos e consumistas adotados pela sociedade contemporânea formam, em conjunto, o cerne da problemática ambiental.

Para que chegássemos a uma possível alternativa estimulou-se a participação ativa da sociedade como uma forma de estabelecer um conjunto que se identificasse com os problemas e soluções estabelecidos dentro da comunidade. Deste modo, possibilitou 
DUARTE, $A . A$. $d e$ $L$; TOFANINI, $B . P . ;$ REZENDE, $M$. G. G.; DUARTE, $R$. $V . d e$

alcançar o objetivo desse trabalho de incitar e disseminar a difusão de conhecimentos ambientais e sustentáveis, produzidos na academia com a participação da comunidade, contribuindo para novas estratégias de preservação e conservação. Nesse sentido, evidenciou-se a relevância desses instrumentos, que realçam as boas práticas, técnicas, e tecnologias sociais apresentadas por meio das cartilhas socioambientais produzidas.

\begin{abstract}
A educação ambiental crítica e emancipatória exige que os conhecimentos sejam apropriados, construídos, de forma dinâmica, coletiva, cooperativa, contínua, interdisciplinar, democrática e participativa, voltados para a construção de sociedades sustentáveis. Muito se tem discutido sobre a educação ambiental e suas formas de realização. Nos vários e diferentes eventos nacionais e internacionais, espaços importantes para a construção de diretrizes filosófico-políticas para a educação ambiental, a busca da sustentabilidade foi apontada como a principal tarefa da educação ambiental (TOZONI, p.1, 2006).
\end{abstract}

Diante do exposto, fez-se necessário a dinamização da Educação Ambiental adentrando pelos vieses epistemológicos, tendo como âmago ferramentas pedagógicas tecnológicas, como as mídias sociais. A plataforma do Facebook (Figura 4), por exemplo, mostra-se essencial para a construção de saberes coletivos e aplicáveis no cotidiano.

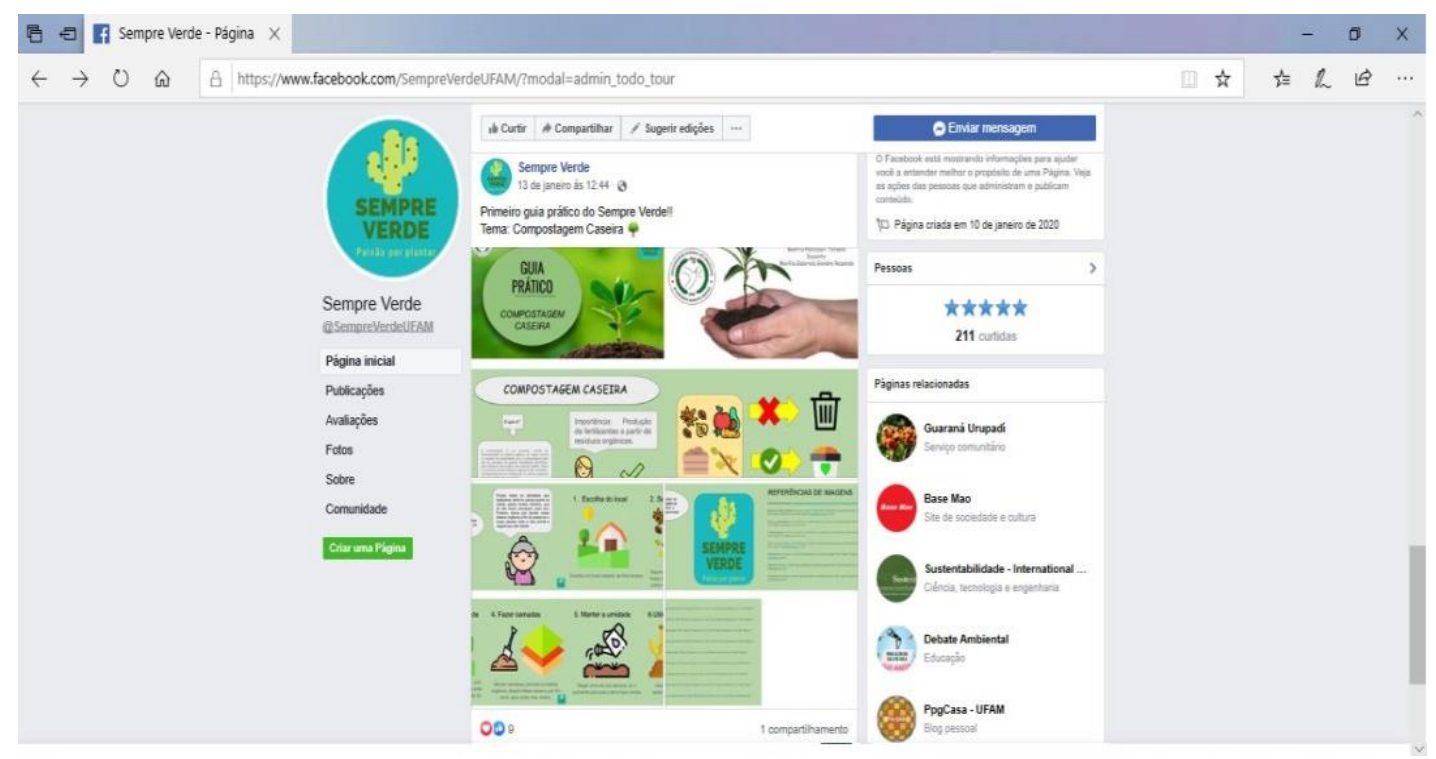

Figura 4: Cartilha socioambiental publicada no Facebook pelo grupo de pesquisa

Fonte: Alexa et al

Portanto, foi imprescindível o desenvolvimento de cartilhas socioambientais ilustradas (Figura 5), que proporcionam a articulação de saberes para a transmissão e aplicação dos conhecimentos voltados à inclusão produtiva e à sustentabilidade socioambiental. Logo, por meio deste artigo, foi possível inferir questões socioambientais 
DUARTE, $A . A$. $d e$ L; TOFANINI, $B . P$. ; REZENDE, $M$. G. G.; DUARTE, $R$. $V . d e$

da Comunidade São Francisco, pois por meio do diálogo foram reveladas abordagens que estimularam a construção de identidades coletivas, bem como processos que asseguraram a participação e mobilização da comunidade.

Figura 5: Primeira cartilha socioambiental produzida pelos discentes da UFAM
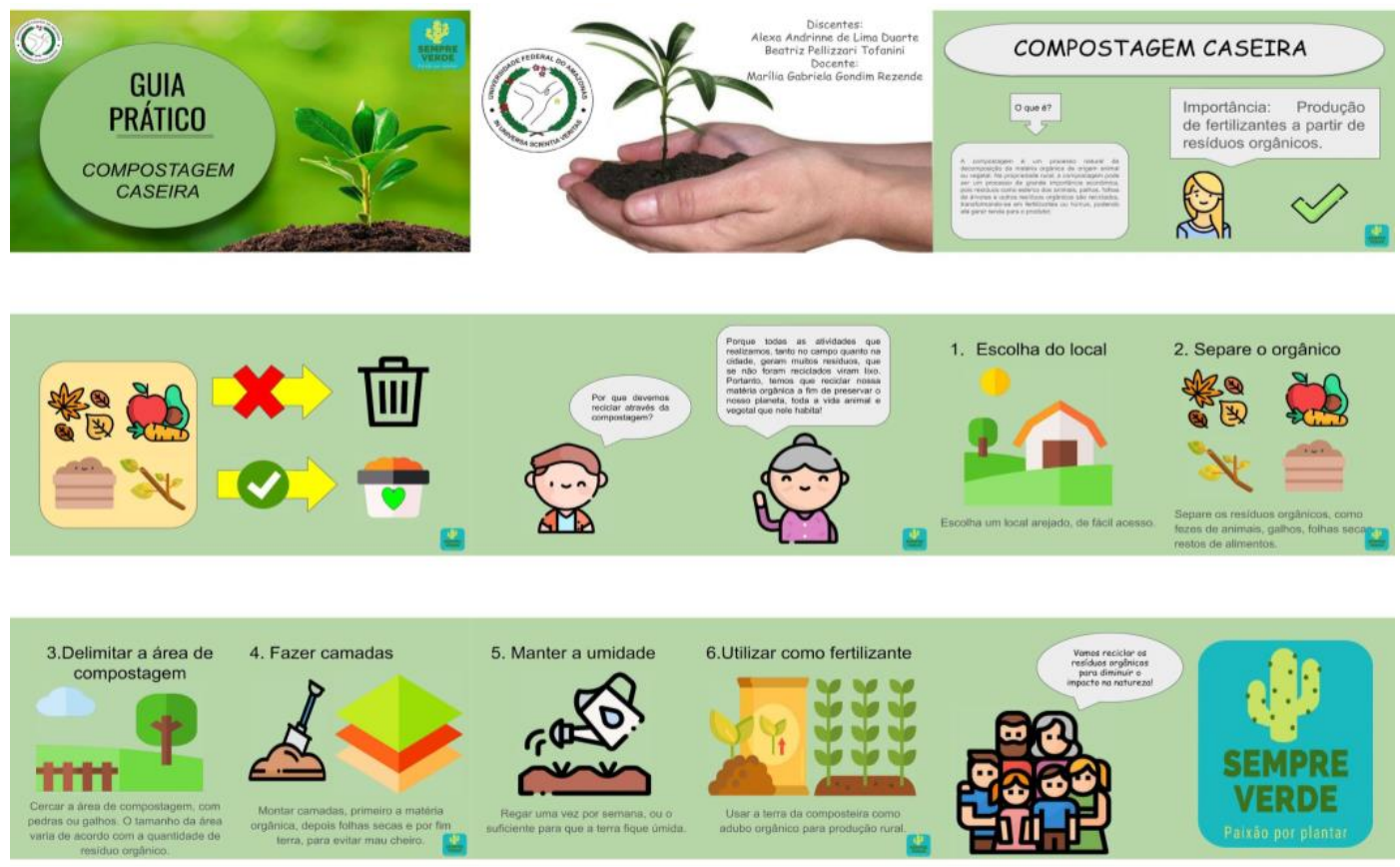

Fonte: Alexa et al

Desta forma, abriram-se caminhos para práticas educativas nos espaços da comunidade, respeitando o contexto ali inserido, demonstrando a importância do protagonismo dos agricultores e demais sujeitos sociais envolvidos para a materialização das práticas de Educação Ambiental e para a ampliação das cadeias produtivas existentes.

As cartilhas publicadas na plataforma do Facebook alcançaram um número significativo de pessoas, conforme Tabela 1, visto que foram disponibilizadas em mídias digitais, inserindo novas diversas formas de ensinar e aprender, além de valorizar o processo de produção de conhecimentos (PARANÁ, 2008, p. 66).

Tabela 1: Dados estatísticos obtido na página do Facebook do projeto. 
DUARTE, $A . A$. $d e$ $L$; TOFANINI, $B . P . ;$ REZENDE, $M$. G. G.; DUARTE, $R$. $V . d e$

Dados do Facebook da Página Sempre Verde

Cartilha 1: Compostagem Caseira

\begin{tabular}{ll|c}
\hline Pessoas alcançadas: & 97 & Envolvimento: 19 \\
\hline \multicolumn{3}{c}{ Cartilha 2: } \\
\hline \multicolumn{3}{c}{ Consai de Romã } \\
\hline Pessoas alcançadas: & $\mathbf{2 1}$ & Envolvimento: 16 \\
\hline Pessoas alcançadas: & 68 & Como regar Plantas \\
\hline
\end{tabular}

Fonte: Alexa et al

Pode-se inferir que as cartilhas socioambientais, quando aplicadas, promoverão diversos impactos positivos na Comunidade São Francisco, bem como o desenvolvimento da própria comunidade por meio da Educação Ambiental contextualizada; melhoria na qualidade de vida dos sitiantes; preservação da fauna e flora; utilização dos recursos de forma sustentável; reconstrução de práticas voltadas à reciclagem; a reutilização e redução dos resíduos sólidos; demonstração da importância do protagonismo dos comunitários para a conservação da sociobiodiversidade; corroboração dos laços coletivistas da comunidade e suas relações interpessoais; promoção do processo de construção do conhecimento coletivo; evidenciação de atitudes de reflexão e ação em torno da problemática ambiental; fortalecimento dos valores coletivos, baseados nas práticas educativas contextualizadas; e a incorporação das tecnologias sociais na produção agrícola.

O Tratado da Educação Ambiental para Sociedades Sustentáveis e Responsabilidade Global que aconteceu no Rio de Janeiro em junho de 1992, paralelamente à Conferência das Nações Unidas para o Meio Ambiente, a Eco-92, reconhece a educação como direito dos cidadãos e firma posição na educação transformadora.

O Tratado convoca as populações a assumirem suas responsabilidades, individual e coletivamente, para cuidar do ambiente:

[...] a educação ambiental para uma sustentabilidade equitativa é um processo de aprendizagem permanente, baseado no respeito a todas as formas de vida. Tal educação afirma valores e ações que contribuem para a transformação humana e social e para a preservação ecológica. Ela estimula a formação de sociedades socialmente justas e ecologicamente equilibradas, que conservem entre si a relação de interdependência e diversidade. Isto requer responsabilidades individual e coletiva no nível local, nacional e planetário. (FÓRUM INTERNACIONAL DAS ONGS, p.1.,1995). 
DUARTE, $A . A$. $d e$ $L$; TOFANINI, $B . P . ;$ REZENDE, $M . G$. G.; DUARTE, $R$. $V . d e$

Logo, a Educação Ambiental consiste em um processo de aprendizagem baseado no respeito à todas as formas de vida. A sustentabilidade, por sua vez, deve ser praticada tanto na individualidade quanto na coletividade. Partindo desse contexto, pode-se afirmar que as cartilhas socioambientais contribuirão para a corroboração das bases do desenvolvimento regional, da inclusão produtiva, e da aplicação de tecnologias sociais, por meio da Educação Ambiental contextualizada.

\section{CONSIDERAÇÕES FINAIS}

A Cartilha proporcionou à comunidade acadêmica a aproximação com a realidade amazônica da Comunidade São Francisco, fazendo com que estes percebessem sob outras lentes o ambiente no qual vivem, os impactos que causam à natureza, desenvolvendo assim o senso crítico e fazendo com que busquem atitudes que possam mitigar os problemas ambientais.

Desta forma, confirma-se a importância de projetos envolvendo a comunidade e a universidade, que instiguem os alunos a relacionarem o que estudam na teoria, sua importância na vida cotidiana e no ambiente, compreendendo sua responsabilidade na transformação do sistema ambiental varzeano.

Além de proporcionar uma admirável oportunidade para os alunos aprenderem de uma forma prática e divertida, ou seja, por meio da criação das cartilhas. Esse material estimulou também a pesquisa sobre os impactos humanos no ambiente, desenvolveu o senso crítico e fez com que buscassem atitudes voltadas à minimização ou resolução dos problemas em questão.

Os conhecimentos gerados na maioria dessas atividades foram entendidos como essenciais para a sensibilização tanto dos alunos da UFAM para alguns dos problemas ambientais da região, como também para os comunitários da área de estudo. Da mesma forma, o momento propiciado aos alunos possibilitou a discussão das questões ambientais, e a construção de materiais didáticos muitas vezes não incentivados e trabalhados em sala de aula. Contudo, acredita-se que essas ferramentas envolvem a responsabilidade de todos, e por meio da Educação Ambiental, constata-se uma lacuna a ser trabalhada dentro da universidade, sob os vieses da interdisciplinaridade. 
DUARTE, $A . A$. $d e$ $L$; TOFANINI, $B . P$. ; REZENDE, $M$. G. G.; DUARTE, $R$. $V . d e$

\section{REFERÊNCIAS}

BRASIL. Lei nº 9.795, de 27 de Abril de 1999.

CONSTITUIÇÃO da República Federativa do Brasil de 1988.

CHIOFI, Luiz Carlos; OLIVEIRA, Marta Regina Furlan. O uso das tecnologias educacionais como ferramenta didática no processo de ensino e aprendizagem. Londrina, 2014.

FÓRUM INTERNACIONAL DAS ONGS. Tratado de educação ambiental para sociedades sustentáveis e responsabilidade global. Rio de Janeiro: 1995.

GIROUX, H. Atos impuros: a prática política dos estudos culturais. Porto Alegre: ARTMED, 2003.

MELLO, S. S. TRAJBER, R. Vamos cuidar do Brasil: conceitos e práticas em educação ambiental na escola. Brasília: Ministério da Educação, Coordenação Geral de Educação Ambiental: Ministério do Meio Ambiente, Departamento de Educação Ambiental: UNESCO, 2007.

PRADO, A. C. et al. TEIA - Tecendo com a Escola a Integração Ambiental. Anais do $4^{\circ}$ Congresso Brasileiro de Extensão Universitária, Dourados - MS. 2009.

SANTOS, Iury Givago Ribeiro Bispo de Almeida; CRUZ, Tiago André da; HORN, Milton Luiz Vieira. Uma breve história das histórias em quadrinhos. Educação Gráfica, Bauru, v. 15, n. 03, p.44-64, out. 2011.

SAVIANI, D. Pedagogia histórico-crítica: Primeiras aproximações, $5^{\mathrm{a}}$ ed. São Paulo, Autores Associados, 1995

Secretaria de Estado do PARANÁ. Diretrizes curriculares da educação básica, 2008, p. 15.

SEIFFERT, M. E. Gestão Ambiental: Instrumentos, esferas de ação e educação ambiental. São Paulo: Atlas, 2009.

REIS, V. R.; SANTOS, A. S.; MACHADO, P. B.; SOUZA, G. S. Utilização de cartilha como ferramenta de educação ambiental, 2012.

REIS, Marília Freitas de Campos Tozoni. Temas ambientais como "temas geradores": contribuições para uma metodologia educativa ambiental crítica, transformadora e emancipatória. Educar Em Revista, 2006.

TRISTÃO, M. A educação ambiental e os contextos formativos na transição de paradigmas. In: REUNIÃO ANUAL DA ANPEd, 30., 2007, Caxambu. Anais... Caxambu: ANPEd, 2007. 